\title{
ANIMAL EXPERIMENTATION
}

\section{Embryonic Dormancy Phenomenon in Obstructed Healthy Mouse Fallopian Tubes}

\author{
ROBERT KUO-KUANG LEE,${ }^{1,2,3,4}$ SHAU-PING LIN,${ }^{1}$ YUAN-JANG TSAI, ${ }^{1}$ MING-HUEI LIN,${ }^{2}$ and \\ YUH-MING HWU²
}

Submitted: April 17, 2000

Accepted: April 28, 2000

\begin{abstract}
Purpose: A mouse model of unilateral oviductal obstruction was designed to study whether healthy oviducts can support embryo development in an advanced stage toward blastocyst hatching and implantation when the embryos in the contralateral side normally move into the uterine cavity.

Methods: The oviducts of 80 female ICR mice (aged 5-8 weeks) were ligated unilaterally $12-40 \mathrm{hr}$ postcoitus. The ligated oviducts were isolated from day 4 to 19.5 postcoitus. Embryos within the ligated oviducts were then flushed out to record the developmental stage and compared with the conceptuses in the contralateral uterine horns with unligated oviducts. Embryos recovered from ligated oviducts were then cultured in vitro to observe their potential for further development.
\end{abstract}

Results: In 33 mice, 53.4\% (163/305) and 86.1\% (241/280) of the morphologically normal blastocysts had hatched from the zona pellucida within the obstructed tube and contralateral uterine horns, respectively, on the 5th day postcoitus. The data demonstrated that the hatching process could take place within the obstructed fallopian tube, but the timing was delayed. From 5.5 to 19.5 days postcoitus, a total of 362 implanted embryos were obtained in unligated control

\footnotetext{
${ }^{1}$ Division of Reproduction and Endocrinology, Department of Medical Research, Mackay Memorial Hospital, Tamshui, Taipei 25115, Taiwan.

${ }^{2}$ Division of Reproductive Endocrinology and Infertility, Department of Gynecology and Obstetrics, Mackay Memorial Hospital, Taipei 10449, Taiwan.

${ }^{3}$ School of Medicine, China Medical College, Taichung, Taiwan.

${ }^{4}$ To whom correspondence should be addressed: Department of Obstetrics and Gynecology, Mackay Memorial Hospital, 92, Sec.

2, Chung Shan North Road, Taipei 10449, Taiwan.
}

uterine horns, but none of the 404 embryos in the artificially obstructed oviducts were implanted. The embryos within the ligated tubes were dormant in the hatched blastocyst stage as demonstrated by their ability to continue growing (98.2\%) when removed from the oviduct to an in vitro environment. Conclusions: In this study, we demonstrate that mouse embryos can hatch, although delayed, in obstructed healthy oviducts. Tubal pregnancy is not likely to happen in artificially obstructed healthy mouse fallopian tubes, since all the viable embryos were dormant at the hatched blastocyst stage.

KEY WORDS: Obstructed oviduct; hatching; embryonic dormancy.

\section{INTRODUCTION}

In mammals, fertilization and early embryo cleavage occurs in the fallopian tubes. Embryos move into the uterus between the third and fifth day of pregnancy where they develop into the blastocyst stage (1). Through hormonally controlled secretions, the oviduct provides a biochemical environment that facilitates, or is even essential for, capacitation of sperm, fertilization, or the early cleavage of embryonic development (2).

The oviduct's contribution toward cleavage stage preimplantation embryo development has been widely studied by comparing embryos cultured in vitro with embryos allowed to develop within the fallopian tubes. Under certain conditions, in vitro zygote development stops at different stages, and this arrest may correlate with the change in transcription of the maternal to the embryonic genome (3). In vitro 
cultured mouse embryos grow more slowly, do not develop endoderm or typical abembryonic trophoblast cells, and have reduced DNA polymerase activity compared with in vivo grown embryos of the same age (4). It also is claimed that coculture of the embryos with oviduct cells in vitro improve blastocyst formation, hatching, and embryo quality (5). This confirms the importance of the oviductal environment for embryo development.

Whether the fallopian environment is suitable for advanced embryo development when the embryos should be normally exposed to the uterine environment is not clear. In the present study, we used mice having undergone unilateral tubal ligation as an experimental model to clarify whether the oviductal milieu can support further embryonic development toward blastocyst hatching or even implantation.

\section{MATERIALS AND METHODS}

Female ICR mice (aged 5-8 weeks) in estrus were used. If they were not naturally in estrus, gonadotropin stimulation was used. The mice were injected intraperitoneally with 5 IU pregnant mare serum gonadotrophin (PMSG) (Sigma, St. Louis, MO 63178), followed by 5 IU human chorionic gonadotrophin (hCG) (Serono, Italy) 46-48 hr later. The animals were placed with males of proven fertility overnight and checked for the presence of vaginal mucus plugs the next morning. Under our controlled lighting schedule (14 hr light/10 hr darkness; lights on at 5 $\mathrm{AM})$, mating and fertilization was expected at midnight, which was taken as time 0 .

Unilateral oviduct ligation was performed in 80 mice from 12 to $40 \mathrm{hr}$ postcoitus. Sodium pentobarbital (1.5 $\mu \mathrm{l} / \mathrm{g}$ body weight) (Abbott Laboratories) was given to anesthetize the mice. Artificial tubal obstruction was accomplished by dorsal entry into the peritoneal cavity and placement of a 4-0 ligature (DEXON "S"; Davis + Geck Inc.,) between the uterine horn and oviduct on one side.

Thirty-three mice were killed by cervical dislocation on the fifth day postcoitus (4 days and 2-19 hr postcoitus) to study whether the embryos could hatch from their zona pellucida within the obstructed fallopian tube. The ligated oviducts were isolated and embryos within the obstructed tubes were flushed out under the dissecting microscope to record the developmental stage. Blastocysts within the contralateral unligated uterine horns were collected sepa- rately and the percentage of hatched blastocysts was recorded to serve as controls.

From 5.5 to 19.5 days postcoitus, 47 mice were killed to inspect whether tubal pregnancy had taken place within the obstructed healthy oviducts. After isolating the ligated oviducts and carefully inspecting for tubal pregnancy, embryos within the ligated tube were flushed out to record their number and developmental stage and compared to the number and developmental stages of conceptuses in the contralateral unligated control uterine horns. Embryos recovered from ligated oviducts then were cultured in minimal essential medium $\alpha$ ( $\alpha$-MEM) (Gibco) plus $10 \%$ fetal bovine serum (FBS) (Atlanta Biologicals) to observe their potential for further development.

\section{RESULTS}

To study whether the embryos retained within the obstructed fallopian tube could develop to the hatching stage, 33 mice were sacrificed on the fifth day postcoitus (Table I). From 4 days and 2-12 hr postcoitus, 54/154 (35.1\%) morphologically normal embryos had hatched from their zona pellucida within the obstructed oviducts, while 113/141 (80\%) blastocysts escaped from their zona pellucida in the contralateral unligated uterine horns. From 4 days and 12-19 hrs postcoitus, $72.2 \%(109 / 151)$ and $92.1 \%$ (128/139) of hatched blastocysts were recovered from obstructed oviducts and contralateral uterine horns, respectively. These data indicate that the hatching process can take place within obstructed healthy oviducts, but the timing of zona shedding was delayed at least $10 \mathrm{hr}$.

The remaining mice were killed from 5.5 to 19.5 days postcoitus to inspect whether tubal pregnancy could occur in obstructed healthy mouse oviducts. In 47 mice, 362 implanted embryos were found in control uterine horns with unligated oviducts, while none were observed in uterine horns with ligated oviducts, indicating the success of tubal ligation (Table II). There was no sign of tubal implantation in the ligated oviducts, even after 19.5 days of gestation when fetus with fetal heart beats could be detected in the contralateral uterine horns.

A total of 404 embryos were recovered from the obstructed oviducts, of which 327 had hatched from the zona pellucida and lay dormant in the hatched blastocyst stage (Table II). Two embryos were at the hatching blastocyst stage. Fifteen blastocysts remained in the zona pellucida. The total of 344 mor- 
Table I. The Development Stage of Morphologically Normal Embryos Flushed from Intact Uteri and Obstructed Oviducts on the 5th Day Postcoitus

\begin{tabular}{|c|c|c|c|c|}
\hline & \multicolumn{2}{|c|}{$\begin{array}{l}4 \text { days and } 2-12 \mathrm{hr} \\
\text { postcoitus }(15 \text { mice })\end{array}$} & \multicolumn{2}{|c|}{$\begin{array}{l}4 \text { days and } 12-19 \mathrm{hr} \\
\text { postcoitus ( } 18 \text { mice) }\end{array}$} \\
\hline & $\begin{array}{l}\text { Obstructed } \\
\text { oviducts }\end{array}$ & $\begin{array}{l}\text { Intact } \\
\text { uterus }\end{array}$ & $\begin{array}{l}\text { Obstructed } \\
\text { oviducts }\end{array}$ & $\begin{array}{l}\text { Intact } \\
\text { uterus }\end{array}$ \\
\hline Blastocysts within zona pellucida & $85(55.2)$ & $24(17)$ & $30(19.9)$ & $8(5.8)$ \\
\hline Hatching blastocyst $(\%)$ & $15(9.7)$ & $4(2.8)^{a}$ & $12(7.9)$ & $3(2.2)^{a}$ \\
\hline Hatched blastocyst (\%) & $54(35.1)^{*}$ & $113(80.1)^{*}$ & $109(72.2)^{* *}$ & $128^{b}(92.1)^{* *}$ \\
\hline Total healthy embryos & 154 & 141 & 151 & 139 \\
\hline
\end{tabular}

a Blastocyst with an open zona pellucida; no trophoblast "knobs" or "buds" were observed in this study.

${ }^{b}$ About $45 \%$ of the hatched blastocysts represent the "cytoplasmic projections of trophectoderm," indicated as the implanting stage.

$* P<0.000001 ;$ chi-square analysis.

** $P<0.0001 ;$ chi-square analysis.

phologically normal embryos from obstructed tubes is close to the number of intrauterine conceptuses found in the contralateral unligated side (362), indicating a comparable incidence of viable embryos in the ligated tubes.

After in vitro culture of the embryos retained in the ligated tubes, 98.2\% (321/327) of the hatched blastocysts reexpended within $24 \mathrm{hr}$, attached to the culture dish, and developed "trophoblast outgrowth" in the following 24-48 hr (Table III). The growth potential decreased from 100 to $85 \%$ after a prolonged dormant period (longer than 11 days after mating). Nine of the 17 blastocysts within the zona pellucida developed further, and 7 embryos completed trophoblast outgrowth in vitro. These results demonstrate that the tubally retained blastocysts were viable but were unable to grow or implant in the obstructed healthy oviducts.

\section{DISCUSSION}

The present study demonstrated that embryos re- tained within the obstructed oviducts could develop beyond the hatching blastocyst stage. However, the hatching process was significantly delayed within the ligated fallopian tube compared with the timing of zona shedding in the contralateral control uterine horns.

Even after 19.5 days of gestation, despite the presence of viable blastocysts, no implanted embryos were found in the ligated mouse oviducts. Those embryos were diapaused in the hatched blastocyst stage. Our data demonstrate that ectopic pregnancy does not occur in obstructed healthy mouse oviducts.

In a similar study, Confino et al. (6) observed two oviductal gestations adjacent to the tubal ligature on day 10 of gestation. They concluded that implantation can occur occasionally in the mouse oviduct when oviductal continuity is interrupted. Variations in the accuracy of the ligated sites limited their ability to explain their results. In a preliminary experiment, we found that if the ligature was placed at the top of the uterine horn, embryos within the oviducts could still move into the uterus. Therefore, it is possible that the gestation sites discovered by Confino et al. were

Table II. The Appearance of Mouse Embryos in Artifically Obstructed Oviducts

\begin{tabular}{lcccc}
\hline & \multicolumn{4}{c}{ Days postcoitus } \\
\cline { 2 - 5 } & $\begin{array}{c}5.5-7.5 \\
(n=18)\end{array}$ & $\begin{array}{c}8.5-10.5 \\
(n=17)\end{array}$ & $\begin{array}{c}11.5-19.5 \\
(n=12)\end{array}$ & $\begin{array}{c}\text { Total } \\
(n=47)\end{array}$ \\
\hline Ligated oviduct & 164 & 135 & 105 & 404 \\
$\quad$ Total number of embryos & 9 & 23 & 28 & 60 \\
$\quad$ Number of degenerated embryos & 9 & - & 6 & 15 \\
$\quad$ Number of blastocysts & 2 & 112 & 71 & 327 \\
$\quad$ Number of hatching blastocysts & 144 & 137 & 95 & 362 \\
$\quad$ Number of hatched blastocysts & 130 & & & 32 \\
Contralateral uterus & Number of conceptuses & & & \\
\hline
\end{tabular}


in the uterine horn instead of the oviduct. To avoid this problem, we ligated the straight segment of the oviduct distal to the uterotubal junction.

In our study, blastocysts in the ligated oviducts remained in a dormant stage after hatching from their zona pellucida. Since most hatched blastocysts attached to the culture dish and developed trophoblast outgrowth after removal from the oviductal environment, we suggest that there were active growth inhibitors present in the normal milieu of the healthy oviducts, which prevented the growth and implantation of viable embryos.

The embryonic dormancy phenomenon observed in artificially obstructed healthy oviducts is quite similar to the dormant stage of preimplantation embryos found in lactating or ovariectomized mice $(7,8)$. It generally is acknowledged that embryonic diapause in mice results from the absence of estrogen during the luteal phase (9). However, the exact mechanisms by which blastocysts arrest in the dormant phase are unclear. It has been proposed that protein factor(s) in the uterine luminal fluid may regulate metabolic dormancy of blastocysts during delayed implantation $(10,11)$. The uterine fluid collected from mice with embryos in diapause inhibits the hatching of blastocysts from their zona pellucida (12). O'Neill and Quinn (13) detected an inhibitor of $\left[{ }^{3} \mathrm{H}\right]$ uridine incorporation in the uterine fluid of ovariectomized mice with diapausing embryos. The activity of the inhibitor was significantly reduced $6.25 \mathrm{hr}$ after an injection of estrogen (13). Some proteins in the uterine luminal fluid decrease or disappear at the time of reactivation by estrogen stimulation. In addition, a potent protein synthesis inhibitor, actinomycin $\mathrm{D}$, has been shown to reverse implantation delay $(9,14,15)$. These studies provide support for the role of uterine-secreted sub- stances-most likely proteins - that inhibit blastocyst development. Katagiri et al. (16) purified a uterine protein from mice carrying diapausing embryos that has inhibitory activity on trophoblast outgrowth. The 170-kDa delayed-implantation-associated protein (DIAP 170K) was found in the uterine tissue as well as in the uterine luminal fluid. The abilities of this DIAP $170 \mathrm{~K}$ to suppress RNA synthesis and cell proliferation as well as to suppress resumption of DNA synthesis by delayed blastocysts may play a role in the regulation of embryonic dormancy associated with delayed implantation $(16,17)$.

In our study, it seems that the dormancy of blastocysts found in the obstructed oviducts was not due to the absence of estrogen secretion. Since we carefully avoided ligating the major blood vessels, we believe that the ligated oviducts and the untreated uterus were under the same blood-borne hormonal support that maintains normal implantation and pregnancy. Therefore, the oviduct might have an embryo growthretarding mechanism or substance similar or identical to the DIAP $170 \mathrm{~K}$ found in the uterus that inhibits the growth of hatched blastocysts within the oviduct (16).

Embryos confined to the obstructed oviducts also fail to develop beyond the blastocyst stage in species like pigs and rabbits, which do not have the embryo dormancy phenomenon. Pig and rabbit embryos in ligated oviducts degenerated and remained within the zona pellucida, while the other embryos emerged from the zona pellucida and were found as conceptuses within the uterus on the nonligated, control side $(18,19)$. To elucidate the mechanism underlying the absence of oviductal ectopic pregnancies, Pauerstein et al. (20) substituted endosalpingeal circumferential grafts for endometrium in a group of rabbits. The endosalpingeal grafts interfered with implantation as

Table III. The In Vitro Developmental Potentail of Embryos Recovered from Artifically Obstructed Oviducts

\begin{tabular}{lcccc}
\hline & \multicolumn{4}{c}{ Days postcoitus } \\
\cline { 2 - 5 } & $\begin{array}{c}5.5-7.5 \\
(n=18)\end{array}$ & $\begin{array}{c}8.5-10.5 \\
(n=17)\end{array}$ & $\begin{array}{c}11.5-19.5 \\
(n=12)\end{array}$ & $\begin{array}{c}\text { Total } \\
(n=47)\end{array}$ \\
\hline Number of hatched blastocysts & 144 & 112 & 71 & 327 \\
$\quad$ Outgrowth of hatched blastocysts & 144 & 112 & 65 & 321 \\
$\quad$ Blastocyst outgrowth ratio (\%) & $100^{*}$ & 100 & $85.5^{*}$ & 98.2 \\
Number of blastocysts and hatching & 11 & - & 6 & 17 \\
$\quad$ blastocysts & 8 & - & 1 & 9 \\
Further development & 6 & - & 1 & 7 \\
Hatched out and outgrowth & 9 & 23 & 28 & 60 \\
Number of degenerated embryos & - & - & - & - \\
$\quad$ Further development & & &
\end{tabular}

$* P<0.0025 ;$ chi-square analysis with Yates correction. 
evidenced by (i) lower nidation indices, (ii) no implantation occurring on the grafted endosalpinx, (iii) unattached blastocysts found within the uterine lumen in the area lined with endosalpinx, and (iv) significantly smaller implantation sites in the uterine horns containing endosalpingeal grafts. Further experiments showed that hatched blastocysts in a cell coculture attached to endometrial but not endosalpingeal monolayers. Moore et al. (21) noted that the addition of conditioned medium from cultured endosalpinx significantly decreased embryo attachment to endometrial cells. These findings suggest the presence of a factor in rabbit endosalpinx that actively suppresses ectopic implantation in the oviduct.

Through our results and the findings described above, it seems that tubal obstruction alone does not cause tubal pregnancy, at least in rodent and porcine fallopian tubes. If human endosalpinx also secretes growth retardation factors, the etiology of tubal pregnancy more likely would be from defects of the endosalpinx caused by inflammation or congenital origins rather than from obstruction alone. However, to clarify whether human oviducts also have the growth retardation effect as we observed in the mouse fallopian tube, we need to identify this factor in rodent oviducts first and then search for the homologous factor in human oviducts.

The putative dormancy inducing factor from rodent oviducts is now under characterization in our laboratory. We hope to identify and purify the embryo-dormancy-inducing factor, which will give us more knowledge related to oviduct anti-implantation mechanisms as well as the etiology of tubal pregnancy. It could become a safe method of contraception.

\section{CONCLUSIONS}

The present study demonstrates that in mice, healthy ligated oviducts can support embryo development beyond the hatching blastocyst stage, but the timing of hatching was delayed compared with embryos in the uterine horns. Tubal pregnancy is not likely to happen in artificially obstructed healthy mouse fallopian tube because all the viable embryos become dormant in the hatched blastocyst stage. When removed from the oviductal environment, almost all dormant hatched blastocysts started to grow, attached to the culture dish, and spread out to develop trophoblastic outgrowth. Thus, we suggest the mouse endosalpinx may secrete factors that result in embryonic dormancy.

\section{ACKNOWLEDGMENTS}

This work was based on research grant NSC 882314-B-195-015 from the National Science Council.

\section{REFERENCES}

1. Harper MJK: Sperm and egg transport. In Reproduction in Mammals I. Germ Cells and Fertilization, 2nd ed, Austin CR, Short RV (eds). Cambridge, England, Cambridge University Press, 1982, pp. 102-127

2. Buhi WC, O’Brien B, Alvarez IM, Erdos G, Dubois D: Immunogold localization of porcine oviductal secretary proteins within the zona pellucida, perivitelline space, and plasma membrane of oviductal and uterine oocytes and early embryos. Biol Reprod 1993;48:1274-1283

3. Bolton VN, Hawes SM, Taylor CT, Parsons JH: Development of spare human preimplantation embryos in vitro: An analysis of the correlations among gross morphology, cleavage rates, and development to the blastocyst. J In Vitro Fertil Embryo Transf 1989;6:30-35

4. Kiessling AA, Davis HW, Williams CS, Sauter RW, Harrison LW: Development and DNA polymerase activities in cultured preimplantation mouse embryos: Comparison with embryos developed in vivo. J Exp Zool 1991;258:34-47

5. Vlad M, Walker D, Kennedy RC: Nuclei number in human embryos co-cultured with human ampullary cells. Hum Reprod 1996;11:1678-1686

6. Confino E, Rawlins R, Binor Z, Radwanska E: The effect of the oviduct, uterine, and in vitro environments on zona thinning in the mouse embryo. Fertil Steril 1997;68:164-167

7. McLaren A: A study of blastocysts during delay and subsequent implantation in lactating mice. J Endocr 1968;42: 453-463

8. Aitken RJ: Changes in the protein content of mouse uterine flushings during normal pregnancy and delayed implantation, and after ovariectomy and oestradiol administration. J Reprod Fertil 1977;50:29-36

9. Finn CA, Martin L: The control of implantation. J Reprod Fertil 1974;39:195-206

10. McLaren A: Blastocyst activation. In The Regulation of Mammalian Reproduction, Segal SJ, Crozier R, Corfman PA et al. (eds). Thomas, Springfield, IL, 1973; pp 321-328

11. Psychoyos A: Endocrine control of egg implantation. In Handbook of Physiology, Section 7, Vol. 11, Part 2, Greep RO, Astwood EB (eds). 1973; pp 201-256

12. Aitken RJ: The culture of mouse blastocyst in the presence of uterine flushings collected during normal pregnancy, delayed implantation and pro-oestrus. J Embryol Exp Morphol 1977;41:295-300.

13. O’Neill C, Quinn P: Inhibitory influence of uterine secretions on mouse blastocysts decreases at the time of blastocyst activation. J Reprod Fertil 1983;68:269-274

14. Finn CA, Downie JM: Changes in the endometrium of mice after the induction of implantation by actinomycin D. J Endocrinol 1975;65:259-264 
15. Camus M, Lejeune B, Leroy F: Induction of implantation in the rat by intraparametrial injection of actinomycin D. Biol Reprod 1979;20:1115-1118

16. Katagiri S, Yuen BH, Moon YS, Takahashi Y, Kanagawa H: Separation of a 170-K delayed-implantation-associated protein with inhibitory activity on trophoblast outgrowth and RNA synthesis by mouse embryo. Am J Reprod Immunol 1994;31:141-150

17. Katagiri S, Takahashi Y, Kanagawa H, Yuen BH, Moon YS: A delayed-implantation-associated protein prevents resumption of DNA synthesis by the trophectoderm of delayed-implanting mouse blastocysts in vitro. J Vet Med Sci 1998;60:791-794
18. Adams CE: Egg development in the rabbit: the influence of postcoital ligation of the uterine tube and of ovariectomy. $\mathbf{J}$ Endocrinol 1958;42:453-463

19. Murray FA, Jr, Bazer FW, Rundell JW, Vingent CK, Wallace HD, Warnick AG: Developmental failure of swine embryos restricted to the oviduct environment. J Reprod Fertil 1971;24:445-448

20. Pauerstein CJ, Eddy CA, Koong MK, Moore GD: Rabbit endosalpinx suppresses ectopic implantation. Fertil Steril 1990;54:522-526

21. Moore GD, Eddy CA, Pauerstein CJ: Rabbit endosalpinx inhibits implantation in vitro. Fertil Steril 1992;57:902-907 